\title{
La historia de la televisión en Cuenca desde su creación: personajes e instituciones
}

\section{The history of television in Cuenca since its inception: Characters and institutions}

\author{
Ludeña Quiroz, Silvio Renato ${ }^{1}$ * \\ ${ }^{1}$ Universidad Católica de Cuenca \\ *renlu9494@gmail.com
}

DOI: https://doi.org/10.26871/killkana_social.v2i1.52

\begin{abstract}
Resumen
Este artículo se refiere a la historia de la televisión en Cuenca, en ese contexto aborda la creación de cada canal existente en la ciudad y a las personas que están al frente de este hito histórico. Las publicaciones existentes son escasas y algunas fechas que se refieren a este acontecimiento no están debidamente estudiadas. Esta investigación recopila las fechas más importantes para la televisión cuencana mediante entrevistas en profundidad a fundadores y protagonistas cercanos a este momento histórico. El alcance de este artículo es exploratorio como un acercamiento al tema tratado, posteriormente descriptivo ya que ahonda en algunos detalles importantes de este acontecimiento. El trabajo tiene un enfoque cualitativo y contrasta la información obtenida de la investigación documental y de las entrevistas. La indagación se realiza en la ciudad de Cuenca, provincia del Azuay, entre enero y julio de 2017. El fin de esta pesquisa es determinar la historia de la televisión cuencana. Este tema aporta con información debidamente sustentada que ayuda a profundizar futuros estudios que se realicen sobre este acontecimiento. La principal conclusión es que este medio de comunicación llegó a la ciudad en 1967, y lo hizo de la mano de empresarios y periodistas de la época quienes no solo implementaron los primeros canales de televisión locales, sino que además crearon nuevos espacios para el periodismo y la información.
\end{abstract}

Palabras clave: Historia de la televisión, Televisión, Primeros canales, Televisión cuencana.

\begin{abstract}
This article reports the history of television in Cuenca. It addresses the creation of every channel that currently exists in the city as well as the people who were leading this historic milestone. The existing publications are scarce and some of the dates with regards to the creation of the channels have not been properly studied. This research compiles the most important historical dates for the television in Cuenca, by means of in-depth interviews applied to founders and protagonists who are closely connected to this historical moment. The scope of this article is at first exploratory in nature, as a means to approach the topic; it later becomes descriptive in nature since it digs into important details. This research work uses a qualitative approach and contrasts the information obtained from documentary research with that obtained from interviews. The research was conducted in the city of Cuenca, located in the Azuay province from January to July, 2017. The aim of this work is to determine the history of television in Cuenca. This study contributes with duly supported information that will help deepen future studies on this subject matter. The main conclusion is that television media first arrived in Cuenca in 1967, with the help of businessmen and journalists of the time, who not only implemented the first local television channels, but also created new room for journalism and information.
\end{abstract}

Key words: History of television, Television, First channels, television in Cuenca.

\section{Introducción}

La historia de la televisión se remonta a 1926, cuando la BBC logra por primera vez transmitir una señal visual, dando paso al nacimiento de este medio; pero no sería hasta la década de los treinta que se transmite un primer programa con regularidad. "Gran Bretaña fue el primer país en iniciar emisiones de televisión con carácter regular en el año 1936, seguida de Alemania, Italia y Estados Unidos, en 1939.
En España, la primera emisión regular tuvo lugar en Madrid el 28 de octubre de 1956"(Tola, 1993). Para (Berwanger, 1977) la televisión no tarda en llegar a los países en vías de desarrollo, siendo México, en 1950, el primer latinoamericano en inaugurar una estación televisiva, seguido por Argentina y Brasil en 1951; completan la lista de los cinco primeros países con televisión en la región República Dominicana y Venezuela en 1952. La televisión 
llega a Ecuador merced a un grupo evangélico. Según (Mora, 1982) el primer programa completo de televisión en Ecuador salió al aire el 31 de julio de 1959 y fue transmitido por Canal $4 \mathrm{La}$ Ventana de los Andes. Este medio, de propiedad de la World Radio Missionary Fellowship, dueña de la radio HCJB Hoy Cristo Jesús Bendice. A la par en Guayaquil el matrimonio Rosenbaum viaja a Alemania y compra equipos para instalar un canal de televisión en Guayaquil.

Con sus equipos y después de lograr trasmisiones exitosas en Quito y Guayaquil, corrigiendo errores técnicos y superando la falta de experiencia, este medio de comunicación aparece en Cuenca con el estadounidense Presley Norton. En ese contexto "El 16 de agosto de 1963, se funda en Cuenca, CANAL 3, que el 12 de abril de 1975 pasa a pertenecer a la Universidad Católica de Cuenca" (Meneses, 1992).

Sin embargo, esta y otras fechas dadas por otros autores sobre este mismo hecho histórico sucedido en Cuenca dejan ver que estos datos no están debidamente estudiados por lo que se hace necesario abordar nuevas indagaciones que permitan responder a la pregunta ¿cuáles son las fechas reales de la historia de la televisión en Cuenca desde su creación? Para lograr el cometido de esta investigación y responder al objetivo, determinar la historia de la televisión en Cuenca, se tiene como base la revisión documental en las bibliotecas de Cuenca y en una biblioteca privada de Guayaquil.

Entre las publicaciones encontradas destacan diferentes autores como Alba Mora Ruiz quien en su libro La Televisión en Ecuador, publicado en 1982, escribe sobre la llegada de este medio audiovisual al país, así como la creación de los primeros canales nacionales y regionales; Zuly Meneses en su obra titulada Análisis de Medios de Comunicación en el Ecuador, publicada en 1992, realiza un examen de las primeras cadenas televisivas y la manera en qué se desarrolló la televisión con el pasar de los años, también presenta datos acerca de las frecuencias dadas a los medios de comunicación a partir de los años sesenta.

Así mismo, en el capítulo escrito por Celia Vázquez del Libro de Cuenca, publicado en 1994, se aborda el tema de la llegada de la televisión a Cuenca y el impacto que causó en esta ciudad. En el marco de los diarios y revistas, es necesario destacar algunas publicaciones como la de la revista Avance No. 197 de 2008 que recoge datos acerca de la creación de Canal 5, de propiedad del periodista cuencano José Cardoso, o la de la revista Tres de Noviembre No. 169 que se refiere a los cuatro canales creados en la ciudad, se trata de Telecuenca, Ondas Azuayas, Telerama y Unsion TV. Posteriormente, la edición de diario El Mercurio del 1 de Diciembre de 2013 aborda la llegada de la primera estación televisiva a la ciudad y presenta algunos datos históricos del canal Ondas Azuayas.

Finalmente, a objeto de tener una visión clara del tema y entender el contexto de la investigación, es necesario definir los términos centrales en esta pesquisa. En ese marco, a la televisión se la entiende como uno de los medios de comunicación con mayor presencia en la sociedad occidental, lo que permite considerarla como uno de los medios básicos de comunicación social que dirige nuestra cultura y los valores que en ella se movilizan (Cerezo, 1994).

Así mismo se concibe a la historia como "un proceso continuo de interacción entre el historiador y sus hechos, un diálogo sin fin entre el presente y el pasado" (Sánchez, 2005).

\section{Metodología}

La investigación tiene su inicio en el análisis hemerográfico, en diarios y revistas, con la búsqueda y revisión del material relacionado a la historia de la televisión en el Ecuador y más concretamente en Cuenca, Esta exploración se realiza considerando que es 1959 el año en que se inicia la primera trasmisión televisiva en el país y que en el año 2003, se da la creación del último canal cuencano Unsion TV. Adicionalmente se hace una revisión de otro tipo de documentos que se refieren a la creación de los medios de comunicación televisivos en Cuenca como son actas, fotografías, afiches, hojas volantes, etcétera.

La presente investigación se realiza bajo enfoque cualitativo y a más de la técnica de revisión documental utiliza las entrevistas de profundidad. Debido al paso de los años y al fallecimiento de algunos personajes, considerados fuentes principales en el presente tema, esta investigación no utiliza una muestra, sino que acude a las personas que vivieron el proceso histórico de la creación de las estaciones de televisión, nombres que fueron obtenidos de la revisión de los registros históricos y en otros casos de las propias respuestas de los primeros entrevistados.

Esta investigación se realiza en el período comprendido entre enero y julio de 2017 en la ciudad de Cuenca. Para efectos de cumplir con el objetivo, interés y argumento del estudio se fijan dos variables. La primera de ellas se trata de la historia y abarca fechas de creación, y la segunda corresponde a los personajes y los canales de televisión que han surgido, han desaparecido y, en otros casos, se mantienen vigentes aún. Al procedimiento metodológico, y luego de la utilización de las técnicas antes citadas, se realiza un análisis de la información y se obtiene como resultado que algunos datos históricos, que aparecen en las publicaciones, son erróneos. Esta indagación permite conocer datos nuevos entorno a fechas, nombres y personajes que estuvieron al frente de estos hitos históricos para la comunicación social cuencana.

Cumplir con este cometido no es fácil por lo que corresponde señalar que existen algunas limitaciones en este estudio como la existencia de pocas obras para el levantamiento del estado del arte, el hermetismo para llegar a las actas fundacionales o la inexistencia de las mismas y, por otro lado, la avanzada edad de algunas fuentes vivas a las cuales ya no es posible entrevistar así como el fallecimiento de algunas otras fuentes primarias valiosas que vivieron este acontecimiento. 


\section{Resultados}

\subsection{Llega la televisión a Ecuador}

La historia de la televisión en el Ecuador se sostiene en 1959 cuando dos personajes, a los que se les atribuye el nacimiento de la televisión ecuatoriana, viajan a Alemania con la idea de comprar equipos para montarse un canal de televisión en Guayaquil. Se trata de José Rosenbaum, un alemán que residía en el Ecuador, y su esposa Linda Zambrano originaria de Manabí. A su retorno al Ecuador, $\mathrm{y}$ radicados en Guayaquil, los esposos empezaron con pequeñas pruebas para sacar adelante su proyecto, pese a la incredulidad de algunos allegados que dudaban de que el intento daría buenos resultados. Y es que la idea de contar con un medio, hasta el momento desconocido, no era fácil de asimilar para los ciudadanos dice Vicente Bowen, sobrino de los esposos Rosenbaum y empleado del primer canal del Ecuador. "La gente se burlaba, por ejemplo, luego de arribar en la Capital el 8 de agosto de 1959 mis tíos realizaron la primera demostración. La reacción de la gente fue irónica, a algunos les causaba risa y les llamaron los telelocos". (V. Bowen, comunicación personal, 7 de enero de 2017).

Ya en el Puerto Principal los esposos estaban decididos a fundar el primer canal ecuatoriano con reconocimiento del estado para lo que había elegido el nombre de Televisora Ecuatoriana Canal 8. Una de las primeras acciones para lograr su cometido fue adquirir una camioneta Chevrolet como la unidad móvil y con ella iniciar una serie de demostraciones del nuevo medio. Con esa idea, el 15 de agosto de 1959 se realizó la transmisión de la feria agropecuaria de Guayaquil, fue una cobertura exitosa que despertó el asombro de las personas, que por primera vez podían verse en la pantalla. Luego de esto, y por una invitación realizada por el empresario Juan Eljuri Chica, la pareja Rosenbaum viaja a Cuenca, hasta dónde trasladan sus equipos a fin de transmitir una feria organizada con motivo de las fiestas de la ciudad. La transmisión se cumple el 3 de noviembre de 1959.

El viaje en esa época no fue fácil, debido al mal estado de las carreteras sobre las que debían transportar los equipos. Ya en la ciudad se instaló una carpa ferial desde la cual se invitaba a los cuencanos a conocer la televisión ecuatoriana por un pago de dos sucres. El evento generó interés y el resultado fue exitoso, lo mismo que ya había sucedido en las presentaciones anteriores. Para entonces la radio quiteña HCJB tenía, al igual que los esposos Rosenbaum, la intención de obtener del estado la frecuencia radioeléctrica que legitime su medio televisivo. Sin embargo, fue el alemán el primero en obtener la frecuencia y en ese contexto la Televisora Ecuatoriana emite la primera señal al aire dentro del territorio ecuatoriano el 12 de diciembre de 1960 a las 17h00. (V. Bowen, comunicación personal, 7 de enero de 2017).

El medio naciente se implementó con programación variada, entrecortada por comerciales de destacadas empresas cuya publicidad se realizaba en vivo. Así, la televisión llegó al Ecuador causando un gran impacto en la población, sobre todo en las pocas personas que tenían acceso a este nuevo medio y que disfrutaban de las primeras imágenes que se emitían en blanco y negro. Con el paso del tiempo, el medio televisivo se fue consolidando como un importante medio para difundir las noticias, la cultura y el entretenimiento divulgadas a través de periodistas de la época quienes implementaron nuevos espacios para el periodismo y la información.

La presencia de Rosenbaum y su esposa en la dirección del canal se extiende hasta febrero del año 1963. El canal se vende a Organizaciones NORLOP, una empresa perteneciente a Presley Norton, un norteamericano que estaba a cargo de Cervecería Nacional, y su socio Alberto López Martínez. Bajo la dirección de estos nuevos propietarios surge la idea de expandir la señal del medio hasta otras latitudes.

\subsection{La televisión llega a Cuenca}

En ese contexto, se instala un canal en la ciudad de Cuenca para que su población pueda observar una producción más local y es así como, después de conseguir la frecuencia radioeléctrica y realizar las primeras pruebas de transmisión, nace el primer canal cuencano el 15 de agosto de 1967. El medio funciona en las calles Benigno Malo y Presidente Córdova, actual edificio de ETAPA.

Bowen confirma que el primer canal nace con el nombre Canal 3 Ciudad de Cuenca de la Red Telesistema del Ecuador. El objetivo del flamante medio era dar continuidad al trabajo que ya se había realizado en Guayaquil a través de un medio de comunicación de programación variada para los cuencanos. Para esa época la tecnología mundial, en especial la televisiva, ya había avanzado significativamente por lo que la calidad de imagen había mejorado ostensiblemente lo que facilitó la entrada del medio en la ciudad. La programación se sostenía merced a programas "enlatados" que se importaban de Estados Unidos, México y Venezuela.

La programación para Canal 3 venía a Cuenca, desde la matriz de Guayaquil, en películas de 16 milímetros. Entre las series de la época que causaron mayor impacto en los televidentes destacan: Tres Patines, Bonanza y El Gran Chaparral. En cuanto a producción nacional, sobresalen los programas Vibra Ecuador, Felicidades Mamá y Cocine con Gusto. La producción local se centraba en la presentación de artistas reconocidos de la ciudad, de la región y excepcionalmente del país.

Al mando de Canal 3, en calidad de gerente, estaba Víctor Hugo Morales, un guayaquileño que gozaba de la confianza de Norton, quien llegó acompañado del sonidista de Televisora Ecuatoriana Walter Murrieta que entre sus principales tareas estaba la de elaborar las cartulinas que contenían los textos publicitarios para los comerciales que aún se emitían en vivo. Tiempo después, Morales deja Cuenca por un nuevo encargo de Norton para que se haga cargo del canal en Manta inaugurado el 20 de Julio de 1968. 
A la salida de Morales, el medio quedó bajo la gerencia de la cuencana Bertha de Veintimilla.

Con el paso del tiempo, la situación económica de la empresa NORLOP se fue desmejorando y no pudo cumplir con ciertas obligaciones bancarias contraídas con el Banco de Préstamos, entidad que terminó por embargar el Canal 3 Ciudad de Cuenca y por ponerlo en remate. Para tal efecto se presentaron tres interesados: el Banco del Pichincha, el licenciado Jorge Piedra y la Universidad Católica de Cuenca (R. Cisneros, comunicación personal, 10 de enero de 2017).

\subsection{Canal 3 cambia de dueño}

La Universidad Católica de Cuenca resultó la organización adjudicataria del remate el 2 de octubre de 1975. Una vez tuvo el canal bajo su propiedad mejoró sus equipos y preparó su salida al aire para el 8 de abril de 1976 , manteniendo inicialmente el nombre Canal 3 Ciudad de Cuenca, palestra cultural, educativa e informativa de la Universidad.

Por esa época ya había canales nacionales, que tenían su señal abierta para Quito y Guayaquil, que querían expandir su señal para otras latitudes y por consiguiente colocar repetidoras en Cuenca. Es así como Teleamazonas pretendía mantener el número 3 , con el que salía al aire en Quito, para su señal en Cuenca. El problema era que este número de frecuencia ya estaba ocupado por el Canal 3 Ciudad de Cuenca. En tal virtud, el Doctor César Cordero Moscoso, como rector fundador de la Universidad Católica de Cuenca y representante del canal local, defendió el derecho que tenía su medio de comunicación. El caso obligó a la intervención del Ministerio de Obras Públicas y Comunicaciones, entidad gubernamental que encontró una salida al adjudicar el número de frecuencia 2 para el canal local y el 11 para el medio nacional (R. Cisneros, comunicación personal, 10 de enero de 2017). En ese marco, el 10 de mayo de 1979, por orden del Instituto Ecuatoriano de Telecomunicaciones (IETEL), Canal 3 Ciudad de Cuenca se cambia al número 2 y además pasa a llamarse Telecuenca e incluye el slogan Canal Universitario Católico, indica Rodrigo Cisneros primer presentador de este canal y posterior gerente del mismo. Con el paso del tiempo, y tras la creación de la carrera de Comunicación Social, sucedida el 29 de julio de 1981, los directivos aspirarían a que el canal sea el centro de prácticas de los estudiantes de dicha escuela, adherida a la facultad de Derecho. Finalmente es 1985 cuando el medio pasa a funcionar en su local propio, de la calle Humboldt y Av. Del Chofer, en donde se mantiene hasta la actualidad.

\subsection{Canal 5 Ondas Azuayas}

El segundo canal que se creó en Cuenca fue Ondas Azuayas. Su inauguración oficial fue el domingo 3 de noviembre de 1968 de la mano del Dr. José Cardoso quien tuvo la idea de renovar la televisión en la ciudad. El evento se dio en el marco de la conmemoración de las festividades de independencia de la ciudad, según lo afirma Diario El Universo del 3 noviembre de 1968, el número de frecuencia asignada fue el Canal 5 de televisión. Sus estudios se ubicaron en las Av. Héroes de Verdeloma entre Luis Cordero y Padre Aguirre. Su presencia significó un importante aporte al desarrollo mediático local que ya contaba con importantes medios entre los que destacaban Canal 3, radiodifusoras y medios impresos con los debía competir por la audiencia.

Debido a que por aquellos años era bastante complejo cubrir los horarios con programación novedosa, este naciente medio de comunicación se encendía al medio día y terminaba su emisión a las 23 h30 señala Luis Bermeo, primer camarógrafo y personaje cercano al fallecido José Cardoso. Uno de los programas que más impacto causó fue El Chavo del Ocho, emisión televisiva que alcanzó un recordado éxito y que se daba en el horario estelar de las 18h00 (L. Bermeo, comunicación personal, 13 de enero de 2017).

La programación de este medio tuvo gran aceptación en el público debido, sobre todo, a que existían acuerdos con Canal 2 de Guayaquil hoy conocido como Ecuavisa. A la producción que llegaba de El Puerto Principal su sumaba la realización propia que tenía una particularidad: se hacía en vivo y en directo, es allí en dónde se destacan los programas Por las Rutas del Recuerdo dirigido por el Dr. Rigoberto Cordero y León, se trataba de una emisión que mezclaba la poesía con la música. Otro de los espacios que tenía gran audiencia fue el que presentaba Galo Orellana Jr. que incluía presentaciones de artistas y que llamaba la atención porque caía un sombrero sobre la cabeza del participante cuando éste cantaba mal.

Otros personajes que destacaron fueron la señora Carmen Estrella Villamana Bretos, más conocida con su nombre de pila Osmara de León, "la bailarina de los pies desnudos" quien se convirtió en la primera presentadora de la televisión cuencana, y es que antes de llegar a Canal 5 ya trabajaba en Canal 3. Se trató de una artista nacida en Cuba y formada en España de donde eran oriundos sus padres. Llegó a Ecuador como parte de una gira artística emprendida por varios países de Latinoamérica, hasta que luego de una de las presentaciones se conoció con el señor Ricardo León con quien decidió hacer su familia y quedarse para siempre en esta ciudad. Ella dirigía un programa enfocado a la mujer cuencana, a las 19 horas, y acompañaba al señor Fabián Molineros en la presentación de noticias, espacio que incluía el editorial que lo presentaba José Cardoso, una persona con temple, caracterizado por decir las cosas con frontalidad y valentía, valores que le hicieron distinguido frente a la teleaudiencia local.

Bermeo indica que Canal 5 brindó la oportunidad a un personaje muy conocido y de una gran trayectoria, se trata del periodista Christian Johnson quien dio sus primeros pasos con un programa concurso que le permitió crecer profesionalmente a medios nacionales y luego internacionales. Canal 5 aportó con coberturas novedosas en la televisión 
local, una muestra sucedió "en el año 1974 cuando pasó el Rally Automovilístico Argentina-México, el canal filmó la competencia que corría por la ciudad de Cuenca y esas imágenes se pasaron en la noche, fue toda una novedad porque antes todo se hacía en vivo" (L. Bermeo, 2017, comunicación personal, 20 de enero de 2017).

Los problemas económicos por falta de publicidad, que permita la adecuada auto sustentación del canal, motivó su venta a Ecuavisa en febrero de 1982.

\subsection{ETV Telerama}

A las seis de la mañana del 3 de noviembre de 1993, y teniendo como marco las festividades novembrinas por la celebración de los 173 años de independencia de Cuenca, nace Telerama. Su visión es crear un formato innovador, educativo y cultural, sus fundadores son Teodoro Jerves junto a Jorge y Juan Eljuri Antón propietario del Banco del Austro. El campo técnico estuvo a cargo del ingeniero Jorge Espinoza, primer director de contenido y productor general, quién contó con el apoyo del ingeniero Oswaldo Carrera para montar las cámaras, editoras y caseteras. "La señal se originó desde los terrenos de radio Sensación, en Ictocruz, debido a que no tenían aún un sitio propio para instalar el transmisor" (J. Espinoza, comunicación personal, 21 de enero de 2017).

En sus inicios, el canal emitía sobre todo documentales de arte, historia, cultura, ciencia, tecnología y música selecta, inclusive clásica. El primer programa que salió al aire en esta estación televisiva fue Contextos e incluía información cultural de Cuenca, estaba dirigido por Diego y Pablo Carrasco. Entre los primeros personajes que hacen parte de este nuevo medio se cuentan María Augusta Romero encargada de los micro informativos, a los informativos se suma la figura de Fernando Reino y después Fernando Correa y Luis Araneda. Con Fabricio Vázquez se inicia el programa musical TV Clip. "Ocho meses después de la creación de ETV Telerama se decide incluir un programa deportivo dirigido por el señor Leonardo Guillén Moreno, elegido para dicha tarea por el señor Jorge Eljuri. Otros programas posteriores pero destacados fueron El Cajón Infantil y Tico Tico" (J. Espinoza, comunicación personal, 28 de enero de 2017). Otras figuras que hacen parte de Telerama son el Dr. Adriano Vintimilla en la administración y Aladino Chaucha y Juan Ávila como sus primeros camarógrafos.

Telerama funcionó en sus inicios en la vivienda del señor Teodoro Jerves y posteriormente se reubica en la casa de la señora Olga Antón, ubicada en la Av. Fray V. Solano y calle Julio Matovelle, desde donde ya se comenzaron a transmitir los primeros micro informativos en vivo. En octubre de 1994 Telerama se traslada para ocupar las actuales instalaciones, ubicadas en la Av. España y Turuhaico, que hasta ese entonces se usaban como bodegas de los almacenes Juan Eljuri. (J. Espinoza, comunicación personal, 28 de enero de 2017).

Luego de casi cuatro años de haber iniciado su señal en Cuenca, el 30 de noviembre de 1997, Telerama abre sus estudios en Guayaquil y casi ocho años más tarde, el 14 de julio de 2001 lo hace en Quito, convirtiéndose en el primer medio televisivo de origen cuencano con alcance nacional. Sin embargo, en 2010 y debido al marco legal vigente, se afirma que los empresarios cuencanos vendieron el canal, una venta que la prensa la reseña de la siguiente manera:

El Grupo Eljuri vendió la televisora para cumplir con el artículo 312 de la Constitución, que prohíbe que grupos financieros tengan medios de comunicación. Telerama es el nuevo nombre de la estación, se le quita el ETV. El canal de cobertura nacional tiene estudios en Cuenca, Quito y Guayaquil. "La línea actual de la programación se conservará en parte, y se incorporará nueva, como telenovelas, noticiarios, deportes, entretenimiento, entre otros enlatados", dijo el colombiano Roberto Dáger, vía correo electrónico. Este funcionario reemplaza a Rebeca Eljuri. El logo de la televisora también cambió. Los colores rojo, azul y blanco cambiaron por un cuadro de rojo más oscuro sobre las letras tele, y rama, en letras negras, con un fondo blanco. El nuevo eslogan de la estación es 'somos más'. (El Comercio, 2010)

\subsection{Unsion TV}

La historia de Unsion TV Canal 25 empieza en abril del año 2003 cuando a William McDonald, más conocido como el pastor "Bill", que llevaba ya varios años dirigiendo a grupos cristianos en Cuenca, le ofrecen una frecuencia para un canal de televisión. "Paco Loor de Guayaquil me ofreció la frecuencia y quería ser mi socio en Cuenca, pero finalmente sólo me vendió la frecuencia. Es así como el 27 de abril de 2003 Unsion TV inicia sus transmisiones, con la misión de ser agentes de influencia religiosa" (W. McDonald, comunicación personal, 15 de enero de 2017). La primera emisión se da en el marco de las celebraciones por los 448 años de fundación de Cuenca, acontecida el 12 de abril de 1557. El naciente canal tiene a McDonald como su presidente, a Eduardo González como su gerente y se inicia con dinero extranjero que procede del apoyo de la misión a la cual pertenece el pastor: Las Asambleas de Dios en EE.UU. A la cabeza de esta institución está la Fundación Unsion Internacional.

Con la idea de hacer de su naciente medio televisivo una ventana evangelizadora que llegue hasta los cuencanos y difundir contenidos de calidad con valores, el canal se instaló en las calles Gran Colombia, entre Esteves de Toral y Coronel Talbot. En este local funcionaba el Club 700 y fue prestado por dicha misión cristiana.

El medio desde sus inicios incluyó programación local. "Inmediatamente empezamos con noticias, con deportes y con un programa de la mañana, llamado En Familia, que era conducido por Gabriel Ferver, Lucia Vinueza y la desaparecida Fabiola Ampuero. Con el paso del tiempo se incorporaron Ana María Apolo y el español Gonzalo González", señala McDonald (Comunicación personal, 15 de enero de 2017).

El primer noticiero producido por Unsion se denominó El Informativo. Su primer periodista, y a la vez conductor y 
presentador, fue Hugo Johnson Humala con la colaboración de Leonardo Ordoñez, recién graduado como licenciado en audiovisuales y contratado como director de noticias. El programa deportivo se inició, y continúa hasta la actualidad, con el señor Guifor Trujillo. Otros personajes que se adhirieron a los informativos fueron Karina Crespo, Jorge Pacheco y Luis Araneda quienes ya antes habían trabajado en Telerama.

"Para poner en marcha el canal, apostamos por personas de confianza y de experiencia y a estos excelentes profesionales sumamos a Rolando Campos como nuestro primer ingeniero encargado de la parte técnica y con Eduardo Gonzáles, quien ha estado firme a mi lado, en la parte gerencial" (W. McDonald, comunicación personal, 25 de enero de 2017).

El canal se vio obligado a mudarse de sitio por cuanto el 29 de marzo de 2006, un voraz incendio consumió gran parte de los equipos y de las instalaciones del canal. "Ante esta situación inesperada, fue la Universidad Politécnica Salesiana las que nos extendió la mano y nos prestó su local. En los laboratorios de la Escuela de Comunicación Social de la UPS estuvimos cerca de tres meses. El incendio fue un momento muy duro pero muy bonito porque mucha gente se unió a nosotros. Recibimos escritos de apoyo de personajes muy importantes como el vicepresidente de la República Alejandro Serrano Aguilar y el Monseñor Luis Alberto Luna" (W. McDonald, comunicación personal, 25 de enero de 2017).

Otro hecho que marcó significativamente la historia de Unsion, fue la muerte de dos de sus jóvenes trabajadores, algo que diario el Universo lo reseñó así:

Fabiola Ampuero, quien fue nueve años presentadora del programa 'En Familia' y el camarógrafo Pedro Jara, ambos de 'Unsion Televisión', estación cuencana, fallecieron la tarde del jueves en un accidente de tránsito en el km 48 de la vía Cuenca-Molleturo-Naranjal. . . Ampuero y Jara regresaban a la capital azuaya tras un evento de Unilever realizado en Guayaquil. El canal suspendió ayer la transmisión temporalmente y declaró el luto por la muerte de los dos profesionales (El Universo, 2012)

Es así como Unsion, y luego de una serie de vicisitudes, sigue funcionando con su ideal de presentar contenido blanco y con valores. Su situación económica le permitió comprar el edificio, ubicado en la calle Juan Montalvo 7 40 entre Presidente Córdova y Antonio José de Sucre, que inicialmente había arrendado tras el incendio. Es desde ese lugar, donde mantiene en la actualidad, desde el que desarrolla un total de 8 horas de producción propia en vivo, varios programas de coproducción y 3 horas diarias de programas pregrabados.

\section{Discusión}

En el desarrollo de la investigación se encontró inconsistencias en relación a ciertas fechas que fueron publicadas en algunas obras y que se refieren a un mismo hecho histórico. Uno de esos casos se refiere a la fecha en la que llega la televisión a la ciudad de Cuenca. La autora Celia Vázquez en su obra La televisión en Cuenca: Trayectoria e influencia, escribe que la televisión se inauguró en Cuenca en 1969, mientras que la publicación de Zuly Meneses manifiesta que 1963 fue el año en que la televisión llegó a Cuenca. En contraste, entrevistado para esta investigación, Vicente Bowen asegura que fue el 15 de agosto de 1967 y como evidencia se respalda en la publicación de Diario El Mercurio del 16 de agosto de 1967 en donde Almacenes JuanEljuri, concesionarios de los televisores Nivico, felicitan a Telesistema del Ecuador "por haber dotado a la ciudad de Cuenca de una eficiente y poderosa estación televisora...". Una copia de esta publicación, difundida un día después del hecho, reposa en la biblioteca particular de Bowen y se presenta como la figura 1.

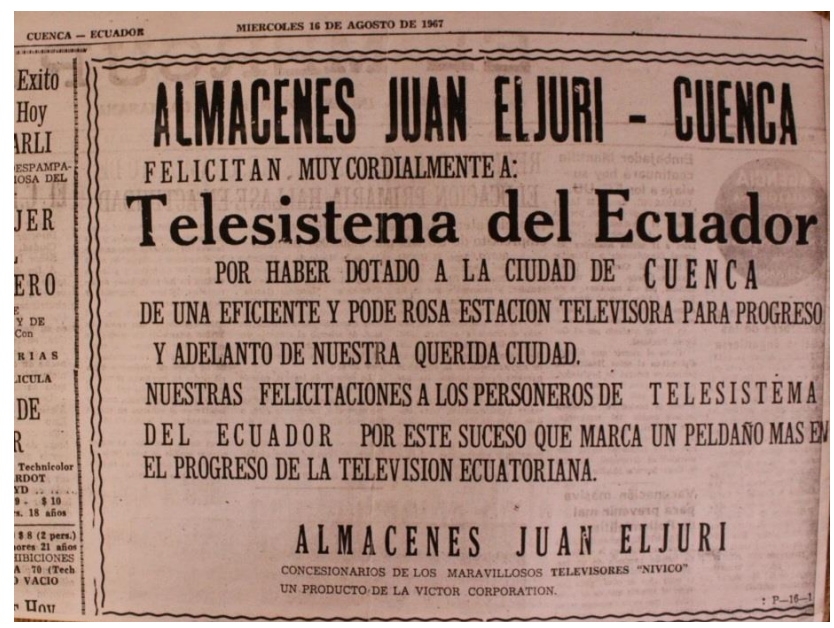

Figura 1. [Fotografía de Renato Ludeña]. (Guayaquil. 2017). Archivos fotográficos de la Biblioteca Privada de Vicente Bowen, Guayaquil.

A la versión de Bowen sobre la que existe evidencia, se añade la del señor Rodrigo Cisneros quien asegura tener acceso a los archivos de Telecuenca y manifiesta que el inicio de la televisión en Cuenca se dio el 9 de diciembre de 1966. Sin embargo, no se facilita el acceso al equipo de investigación hasta esos archivos y se brinda la entrevista solicitada.

Otro aspecto importante que es menester citar en este acápite es la fundación oficial del Canal 5 Ondas Azuayas cuya fecha de su inauguración varía en diferentes publicaciones. A saber: en la revista Tres de Noviembre número 169 se señala "Este fue otro canal de televisión cuencano que nació el 12 de abril de 1967". p. 140. Por su parte la revista Avance edición 197 cita "el afán de renovación y actualidad llevó al Dr. Cardoso a fundar, en 1968, el Canal 5 de Televisión”. Frente a estos datos publicados, fue necesario hacer un barrido en los diferentes periódicos de la época encontrándose que diario El Universo da a conocer la fecha exacta de la inauguración oficial de este medio. Se trata del 3 de noviembre de 1968 y como evidencia se muestra la imagen 2 en donde se confirma que Ondas Azuayas Canal 5 se inaugura el domingo 3 de noviembre de 
1968 en el marco festivo de las fiestas por la independencia de Cuenca.

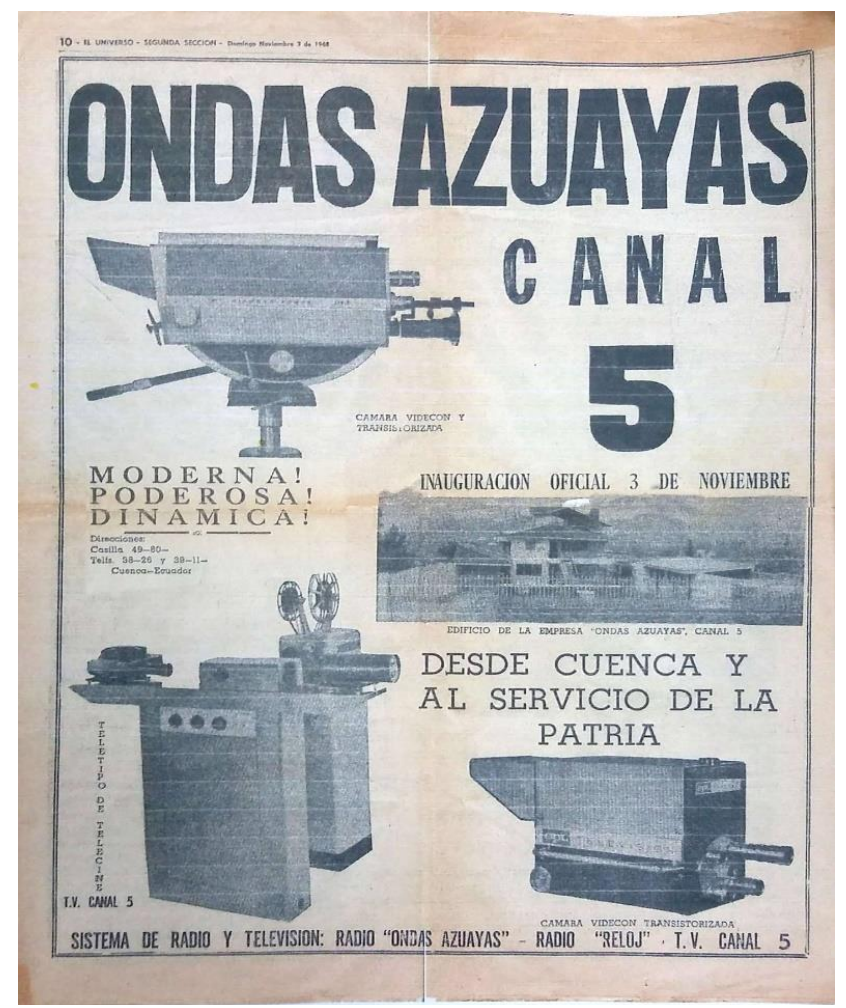

Figura 2. [Fotografía de Renato Ludeña]. (Guayaquil. 2017). Archivos fotográficos de la Biblioteca Privada de Vicente Bowen, Guayaquil.

Las fechas de creación Telerama y Unsion TV no hacen parte de la discusión por cuanto tanto las fuentes documentales cuanto las fuentes vivas coinciden en su totalidad.

\section{Conclusiones}

Aunque el tema planteado está poco tratado, las fuentes utilizadas en esta investigación permiten aportar fechas y datos valiosos en el objetivo de este trabajo que es determinar la historia de la televisión cuencana. En ese marco, se asume que fue 1967 el año en que llega la televisión a Cuenca y hace impulsada por empresarios y periodistas de la época que implementaron los primeros canales de televisión locales y que además crearon nuevos espacios para el periodismo y la información.

La historia de la televisión cuencana tiene una gran importancia y la ciudadanía debe conocer y reconocer a las personas que hicieron posible que este medio haya llegado a Cuenca y que conozca el valor que abarcó ese proceso.

Todas las personas citadas en este artículo, algunos ya retirados, otros fallecidos y los demás aun laborando en medios de comunicación, fueron muy importantes en el avance histórico de la televisión en cada una de las tareas que les correspondió cumplir. Algunos de los personajes mencionados en la presente investigación, en especial en los últimos canales que fueron creados, mantienen vigente su renombre en el ámbito periodístico.

Cada cierto tiempo, el personal de los canales de televisión se renueva lenta pero constantemente y aunque esto aporta frescura a cada espacio televisivo y surgen nuevos nombres, es fundamental para la memoria colectiva, histórica y cultural rescatar y destacar a quienes hicieron parte del pasado.

Finalmente, la presente investigación revela que el tema no está agotado y que la historia de la televisión cuencana puede seguir enriqueciéndose mediante nuevos estudios que aporten y saquen a flote datos que aún son desconocidos. En tal virtud queda aún pendiente realizar investigaciones que puedan orientarse al aporte social, cultural y económico que generó este medio desde su llegada a la ciudad. También es una pesquisa pendiente efectuar estudios de maestría y doctorado en el campo de la historia de los medios de comunicación en Cuenca algo que aún no ha sido abordado en su totalidad.

\section{Referencias Bibliográficas}

Aguirre, J. O. (2013, 1 diciembre). La primera señal televisiva llegó en 1967. Descargado de https://www.elmercurio.com.ec/ 407922-la-primera-senal-televisiva -llego-en-1967/

Arriaza, M. (1994). Texto, contexto y situación. España: Octaedro S.L.

Bernal, C. (2006). Metodología de la investigación para administración, economía, humanidades y ciencias sociales (Segunda ed.). Pearson Educación.

Berwanger, D. (1977). Cine y televisión a bajo a costo. Quito: Intiyan.

Cerezo, M. (1994). Teorías sobre el medio televisivo y educación: el discurso de la televisión. Granada: Grupo Imago.

Delgado, G. (2010). Conceptos y metodología de la investigación histórica. Cuba.

El Comercio. (2010, 20 diciembre). Telerama cuenta con nueva imagen. Descargado de http://www.elcomercio.com/ tendencias/entretenimiento/telerama -cuenta-nueva-imagen-1.html

El Universo. (1968, 3 de noviembre). Se anuncia inauguración de ondas azuayas.

El Universo. (2012, 17 de mayo). Periodista y camarógrafo de canal Unsión TV de Cuenca mueren en accidente de tránsito. Descargado de https: / / www.eluniverso.com/2012/05/ $17 / 1 / 1422 /$ periodista-camarografo -canal-unsion-tv-cuenca-mueren -accidente-transito.html

Guerrero, R. (2010). Historia de la Televisión en el Ecuador y en la ciudad de loja. Loja: UTPL. Descargado de https://www.utpl.edu.ec/ jorgeluisjaramillo/wp-content/ 
uploads/2010/06/roberto_guerrero

-historia-de-la-TV-en-Ecuador-y-en

-Loja.pdf

Meneses, Z. (1992). Análisis de medios de comunicación en el ecuador (Vol. 2). Quito, Ecuador: CIESPAL.

Mora, A. (1982). La televisión en el ecuador. Editorial AMAUTA. Descargado de

https://books.google.com.ec/

books?id=yt JjAAAAMAAJ
Salvat, J. (1979). Enciclopedia salvat del estudiante. Ecuador: Salvat Editores Ecuatoriana S.A.

Sampieri, R., Collado, C., y Lucio, P. (2014). Metodología de la investigación (Sexta ed.). McGraw-Hill Education. Descargado de https://books.google . com. ec/books? id=oLbjoQEACAAJ

Sánchez, S. (2005). ¿y qué es la historia? madrid: Siglo $X X I$.

Tola, J. (1993). Atlas de las comunicaciones. Colombia: Panamericana Formas e Impresos S.A.

Recibido: 30 de octubre de 2017

Aceptado: 2 de enero de 2018 